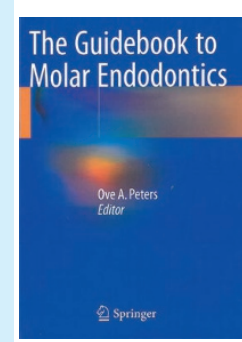

THE GUIDEBOOK

TO MOLAR ENDODONTICS

Ove A. Peters

2017

Springer

price $\mathrm{f} 108$ pp. 298

ISBN: 9783662528990

This book contains a comprehensive summary of the diagnosis and treatment of molar endodontic issues. It is the product of an extensive international collaboration of endodontists and other dental specialists. The book is primarily aimed at endodontic specialists, but also general dental practitioners wishing to further their knowledge and skill set in relation to molar endodontics.

The book comprises ten logically sequenced chapters, beginning with molar root canal anatomy (chapter 1). Diagnosis of pulpal status (chapter 2 ) is followed by local anaesthesia and vital pulp therapy (chapters 3 and 4). Establishing appropriate access to the root canal system and the procedure of cleaning, disinfecting and obturation are covered in chapters 5 and 6 . The process from diagnosis to obturation is covered in depth, with helpful problem-solving tips. Vital pulp therapy is given due attention, with well-detailed case selection and methodologies, including coronal pulpotomies for teeth exhibiting irreversible pulpitis symptoms.

Subsequent restorative considerations are included in chapter 7, with a useful discussion of the coronal seal, cuspal coverage, post placement and CAD/CAM endocrowns. However, the omission of root resection and hemi-section (premolarisation) as a treatment modality for molars with one compromised root is a shortcoming; emphasis has instead been placed on the treatment and retention of the whole tooth. Chapter 8 covers the outcomes of endodontics and correctly draws attention to the discrepancy of clinician - and patient-defined successes. The authors also highlight that there is a heterogeneity of defined outcomes alongside 'knowledge gaps' in existing endodontics literature that require high-quality studies to address in future. Re-treatment, both surgical and non-surgical, are explored in chapters 9 and 10 respectively.
Both chapters provide useful information for appropriate case selection, and step-bystep accounts of the techniques required to achieve the desired clinical result.

Praise must be directed towards the impressive catalogue of clinical cases with accompanying photos and radiographs throughout, with many demonstrating follow-up over several years. Diagrams and tables helpfully summarise large bodies of text, with a particular highlight being the use of micro-CT diagrams to illustrate variable molar root canal morphologies. The text includes citations to recent scientific journals and is thus strengthened by reference to current evidence-based practices.

Overall, this is an excellent publication on molar endodontics; it provides a wealth of accessible information for postgraduate students and general dental practitioners alike. The editor has successfully compiled an essential new reference book for both personal and professional dental libraries.

James Nelson

Available to buy from the BDA shop: https:// shop.bda.org

\title{
UK dental practices are struggling to fill roles
}

Dental recruitment is going through a difficult period in the UK, and this is beginning to affect the profession.

According to Dental Elite, who advise dental practices on recruitment, practice sales, acquisitions and finance, it is not just smaller, independent practices that are struggling to recruit, but the large groups and corporates as well, even in the South East.

An article published on Dental Elite's website (http://bit.ly/2CYQAAv) presents the example of Anushika Brogan, Managing and Clinical Director of Damira Dental Studios Ltd, who revealed that a role advertised in Oxford in 2017 attracted just one candidate who had ten other interviews lined up.

An expert panel set up by Dental Elite examined how difficulties in getting a performer number has had a knock-on effect on recruitment. Processing performer numbers can now take longer than a year, which makes it difficult to source new recruits from other European countries who also often need six months of vocational experience and must be prepared to take on a lot of administration in their UK roles.

The expert panel also considered that new dental graduates are thought to have a greater fear of being sued than previous generations of dentists, which has affected their delivery of UDAs - meaning that more practices are struggling to meet their UDA target, impacting profits and the bottom line.

James Richards, Classified Advertising Manager at BDJ Jobs, was asked for his perspective on the recruitment problems in dentistry and said: 'Last year employers received fewer applications than previous years as the market has swung in favour of the job seeker rather than the employer. This could be attributed to uncertainty due to the general election and Brexit, as well as young dentists leaving the NHS as documented by the BDA (http://bit.ly/2xVhCpe).

'We have seen many examples of job listings with a high number of views but only a few applications, for example a current listing has been viewed over 600 times but only received eight applications. In 2017 we surveyed visitors to BDJ Jobs and of all the jobseekers who replied to the survey, $63 \%$ indicated that they had found a job on the site for which they applied. Positively, of these, $82 \%$ found a job for which they received an offer. In order to convert the other $37 \%$ of jobseekers into applicants we are working with employers to help improve the content of their adverts so they sell their role appropriately and develop their employer brand.

'In the survey $32 \%$ of job seekers stated they used BDJ Jobs to research recruiters by visiting employer profiles. The employer profiles are free for all advertisers and can help convey what makes their practice a great place to work. When buying a car or another expensive item consumers research the product before buying; the same applies with recruitment.

'Our team is here to help. We can provide guides to writing job adverts and set up employer profiles so that you get the most from our services.' 